\title{
Crossing Border: The Acculturative Experiences of a Chinese Migrant Academic New Zealand Mingsheng Li
}

School of Communication, Journalism and Marketing, Massey University, Palmerston North 4474, New Zealand

Abstract
This case study examines the acculturative experiences of a Chinese academic in New Zealand. It
describes his dilemmas in his life choices whether to return to China or not after his doctoral study, and
reports the plights, hardships, and setbacks he had experienced in settling down and seeking employment
in a new country. The case study, through a narrative approach, uncovers some of the under-researched
issues facing new migrant professionals in higher education institutions in New Zealand, including
workplace bullying, discrimination, racial inequality, racism, lack of opportunities for career development,
and impenetrable glass ceilings in academic promotions. It highlights the disadvantages of the Chinese
migrant's low-key, non-direct and non-assertive communicational styles and relational strategies in the
workplace contexts in New Zealand higher education institutions that hinder the crossing of culturally
constructed relational fences and, most importantly, career advancement and promotions.

Publication History:

Received: January 24, 2016

Accepted: December 29, 2016

Published: December 31, 2016

\section{Keywords:}

Migrant, Employment, Workplace Bullying, Racism, Discrimination, Communication styles, Acculturation

\section{Introduction}

Internationalisation has become one of top priorities in universities in many developed countries. It has become a benchmark in assessing a university's success, reputation, and it's positioning in the world. In the QS world university rankings, two indicators of internationalisation international student ratio and international staff ratio are used to assess how successful a university can attract international students and faculty members from other nations, and thus assess the reputation and ranking of the university. Enrolment of international students can contribute enormously to universities by generating revenues to help ease the financial difficulties facing universities as governments reduce educational budgets. Universities compete with one another to attract as many international students as possible. The presence of international students is broadly welcomed.

To promote educational quality and enhance the reputation, many universities make persistent endeavours to attract faculty members from other cultures and nations. In New Zealand universities, international faculty members from non-English-speaking backgrounds (NESB) have become an integral part of the higher education system. A large majority of them have received their advanced degrees in developed countries. Their presence in higher education contributes to internationalisation but also has caused some contentions in the predominantly white community about their backgrounds, performance, cultural values, beliefs, language competence, communication skills, and pedagogical philosophies, expectations, and practices. Many NESB instructors perceive great disparities in the treatment by colleagues and senior leaders in an inhospitable education environment. They have to struggle to survive in a higher education institution that is expected to take a leading role in addressing social ills and to "affirm their worthiness, reward their contribution, support their worldviews, and value their participation" [1]. However, this has not been the case. A substantial number of NESB faculties have experienced exclusion, alienation, marginalization, overt and covert racism, institutionalized discrimination, and status inequality. They remain both highly visible and invisible in different moments of organisational life: visible because of their salient racial, cultural and linguistic differences, invisible because of the organizational denial of their perspectives, interests, contribution, rewards, and promotions. These NESB faculty members can only engage in legitimate peripheral participation in the community practice, but never gain full membership and identity of the community of practice [2]. Their concerns, plights, pains, struggle, voices, racial and ethnic biases, and glass ceiling effects have been under-researched.

This case study, using the voice of a fictitious character named Xiang Qin, reflects these struggles, pains, personal experiences and "the on-the-ground reality of institutionalized discrimination" in higher education" [1]. The case study starts from Xiang's motivations of migrating to New Zealand and his plights in seeking employment. Having acquired a doctoral degree from an American university did not give him any advantage in the New Zealand labour market. His linguistic, ethnic and cultural backgrounds became barriers in accessing suitable jobs in the country. When he eventually found an employment, he could not escape interpersonal and institutional racism, and workplace bullying and discrimination by his colleagues and senior management. His culturally different communication styles were found unfit in the New Zealand workplace where socialization and social networking were critical contributors to career advancement. Finally, the case demonstrates the difficulties, the impenetrable glass ceilings in academic promotion, and the dark side of interpersonal issues that Xiang bitterly experienced in a New Zealand university. It is important to note that the names, the stories, events, and issues described in this case study are in no way linked with a particular university or a particular person.

\section{Case Presentation}

\section{To return or not to return?}

Xiang Qin had been an associate professor, teaching International Relations at a university in Central China. He also had a five-year managerial experience as Vice Dean of his department. He went to pursue advanced studies in an American university under a

*Corresponding Author: Dr. Mingsheng Li, School of Communication, Journalism and Marketing, Massey University, Palmerston North 4474, New Zealand; E-mail: M.S.Li@massey.ac.nz

Citation: Li M (2016) Crossing Border: The Acculturative Experiences of a Chinese Migrant Academic New Zealand. Int J Journalism Mass Comm 3: 123. doi: https://doi.org/10.15344/2349-2635/2016/123

Copyright: @ $2016 \mathrm{Li}$. This is an open-access article distributed under the terms of the Creative Commons Attribution License, which permits unrestricted use, distribution, and reproduction in any medium, provided the original author and source are credited. 
scholarship, hoping to become a researcher and scholar in International Relations in the future. His former university considered him a star and promised to retain his academic and managerial positions until his return. During his stay in the U.S.A, some senior leaders from his university visited him, encouraging him to complete his study and return to the university to take up his positions. He worked very hard and finished his study in four years.

However, Xiang was struggling to find an answer to the question: to return or not to return? Returning to China, he had a very promising future awaiting him: professorship, senior managerial positions, housing, research funds, and high self-esteem; not returning to China would mean an unpredictable future. The biggest problem facing Xiang was his daughter's education. In spite of his intensive lobbying, not a single school in his home city would like to accept his 14-yearold daughter, the only child in the family. The reason given was very simple: her 4-year absence from the Chinese education system would be a barrier for her to catch up with the rest of the cohort and that would contribute to the lowering of the pass rate to senior high schools. This would be a blemish to the principal's scorecards. It was unthinkable to Xiang and his wife that he had obtained a doctoral degree but his daughter had been denied any rightful access to schooling in China. Frustration, helplessness, anger and a sense of guilt to his daughter overwhelmed him. Yet, the family could not afford her studying as an international student in the USA. The combined monthly salaries at the time amounted to $\$$ US170, not enough for a one-week homestay expense. Taking all into account, the family decided to migrate to New Zealand where the daughter could continue her Western education without violent interruptions. This meant that Xiang would have to lose all he had obtained in China: employment, social and cultural capital, guanxi (social connections and relationships), reputation, and cultural roots. It was indeed a very tough decision to make. However, the Chinese tradition of sacrificing oneself for the benefits of the next generation became a predominant factor in the decision-making. The family arrived in Auckland. Xiang's daughter was admitted into a school where she later received many awards and prizes. Her home country's schools rejected her, but the New Zealand school gave her an opportunity to develop her potential. She has now become an emerging business leader in New Zealand.

\section{Seeking employment in New Zealand}

Xiang felt relieved that his daughter had found a very good and welcoming school. One significant challenge was awaiting the family: seeking employment. Finding a suitable job in a higher education institution was his current life priority. However, having searched the Internet and newspapers, he could not find any suitable vacancies. The family was frustrated. There was no income to pay the high rent and other expenses. In the third week, Xiang and his wife found a job as a worker in an electronic company, earning $\$ 9$ per hour. When filling the job application form, Xiang put "high school graduation certificate" in the "qualification" box, deliberately hiding his actual qualification. There was no need to tell the truth, anyway. No company would hire a $\mathrm{PhD}$ for such menial jobs. He was extremely happy to find a job to help the family to settle down well. At least the income was good enough to pay the rent, food and power bills. He never lost any time looking for jobs. Having mailed more than one hundred applications with his CV, in twelve months, Xiang had obtained three interviews only. His heart sank after each interview.

The first interview was a lecturer's position in International Relations in a polytechnic. The interview panel was impressed with his presentation and publications. A week after the interview, he received a phone call from the chair of the department, advising him of his unsuccessful application for one simple reason: he did not have any learning and teaching experiences in New Zealand, although he had very rich teaching experiences in China. The university would not risk recruiting people without local experience and without a solid understanding of the New Zealand educational system.

The second interview was a job as marketing manager in a language school where all students came from Asia, mostly from China. The principal interviewed him. She was stunned at Xiang's academic achievements and his publication records. She was also interested in his track records of recruiting students from China for the university where he had studied his PhD. Having gone through the interview ritual, she concluded: "I cannot employ you for this job. You are overqualified. I myself do not have a bachelor degree. How can I manage somebody with a doctoral degree? However, we would give you commissions of $3-5 \%$ of the paid tuition fees for the students you have recruited for us."

The third interview was for a position as a Chinese-English translator for a Chinese newspaper. He walked into the room, and the manager of the company gave him a piece of news article from a newspaper New Zealand Herald, about half of a page, asking him to translate it into Chinese within two hours. He finished the translation within the time limit. The manager did not "interview" him. Instead, she gave him a book, asking him to translate it into English within two weeks, without mentioning whether the company would employ him or not and whether he would get paid for his translation. The next day, the article he had translated was published in the newspaper. Xiang told one of his friends about the job vacancy. His friend told him that it had been the company's trick to trap job hunters to do "voluntary" work without paying. His friend himself and many others who were hungry for employment had been victimised by the company.

Having worked on an assembly line for over a year, without any hope of having access to a decent job, Xiang felt frustrated, stressed and depressed. He did not realise that getting a job was extremely difficult in New Zealand. He began to lose confidence and his selfesteem was thwarted. His glorious past became salient in his memory. The sharp contrast of this past and present made him even more depressed. His talent had been totally wasted. He could have used his talent to do many other important things for New Zealand. He was thinking of returning to China to revive his past glory. However, he was trapped. The family life would not allow him to nurse such an idea. He had to continue to look for jobs, with stronger determination and perseverance.

\section{Getting employed at last}

Losing the one-year battle in finding an employment required a creative and critical thinking. Xiang Qin changed his name to sound like an Anglo-Saxon one: Sean Chase, which was close in sound to his Chinese name. With this changed name, he submitted his application for a lecturer position in international relations in a polytechnic. $\mathrm{He}$ made sure that he remembered his new name and new identity. One week after the deadline, he received a letter, advising him that he had been shortlisted for an interview. The polytechnic booked the flights and prepared the taxi chits for his interview. When he arrived, the interview panel was surprised that the person they were going to interview was not a European, but a Chinese. He explained to them 
that he used an Anglo-Saxon name to make it easy for them because his Chinese name, Xiang Qin, was difficult for them to pronounce. The panel was very satisfied with his oral presentation, his research outputs, and his previous academic and teaching experiences in China and in U.S.A. He was the right person the institution was looking for.

Two weeks after the interview, he received a job offer. Three weeks later, he took up the position. Xiang began to feel that his selfconfidence and self-esteem had crawled back. He felt he was very lucky to find this job. He was determined to excel in his work performance to demonstrate his gratitude to the polytechnic that saved him from the deep gloom.

A week later when he was enjoying morning tea with Trevor and the other two colleagues who had been on the interview panel, Trevor disclosed to him a piece of confidential information: His recruitment went through a serious fight between the interview panel and the dean of the faculty who strongly rejected the panel's recommendation to recruit a non-native English-speaking Chinese. He preferred the applicant from the UK that the panel placed as a second choice. The panel eventually went straight to the CEO of the polytechnic. The CEO's involvement and arbitration were in favour of the panel's decision. This recruiting practice led to the tension between the dean and the head of the school.

Hearing this shocking story, Xiang felt very uneasy. He sensed that some of the colleagues seemed to have a positive attitude towards him, and they tended to be friendly, but the history of this saga had placed some shadow over his career path and over his bumpy border-crossing to the academic culture in a New Zealand higher education institution. Even before he was formally ushered into the academic arena, he had already been "otherised" and his ethnic and cultural differences had become barriers to his career advancement. His previous excitement and enthusiasm were now replaced with uncertainty and uneasiness.

\section{Workplace bullying and racism}

Xiang was to teach two distance learning courses in the semester, together with other two colleagues, who had been teaching these two courses for more than ten years. As a new comer, he had a lot to learn, not about academic issues, but about routine procedural matters, such as writing study guides and assignments, marking, giving feedback, moderating, online tutoring, use of the student management system, and workshops. He had acquired much experience in lecturing, but he was a green hand in distance education. His past teaching experience and pedagogical skills were not transferable to the current academic environment where lecturers rarely saw their students, except for the occasions at workshops, and "teaching" was undertaken through emails, telephone calls, and the Moodle (anonline learning platform to create personalised learning environments for online learning).

The mentoring system did not exist at the polytechnic. The new employee was expected to learn new rules, written or hidden, all by themselves, sink or swim. It took Xiang a long time to have a good knowledge of these rules of the games. He would not admit that he was a superb game player, but knowing these game rules enabled him to navigate the course of his career development. However, mastering of these game rules came at a high price: He acquired them by undergoing workplace bullies and harassment.

As a newcomer from a non-native English-speaking background, working with colleagues who were born and had been working at the institution for their whole life, Xiang became an easy target of radicalized exclusion, racial discrimination, and bullying.

Xiang was invited to moderate the markings by John Peters, one of his colleagues. Moderation is a general process of lecturers sharing the standards and criteria in assessment through a blind-folded approach to achieve consistency and equivalence in course delivery and assessment. It is an important system set up in the polytechnic where all the courses are to be yet moderated by scholars and experts from New Zealand universities. Xiang worked seriously on all the scripts sent for moderation. It was natural that there were some disparities between each other's marking; the difference of ten per cent was allowable. When seeing the huge disparity (62\% versus $93 \%$ ), John flew into a rage, red faced, yelling: "How dare you mark my top student down from $93 \%$ to $62 \%$ ? I have been very nice to you but see what you have done. You bugger. You dirty Chinese!". Xiang listened quietly, but seriously hurt, highly upset. A kind of pedagogical practice created such an unpleasant situation. A third person was invited to mark the questionable assignment and the marks were lower than Xiang's, $58 \%$. Finally, the three people sat together and came to a consensus: $65 \%$. For many days, Xiang could not sleep well. The racial taunts, slurs, yelling, and brutal bullying made him re-assess his situation, his unequal status. He had become a victim of interpersonal racism in the workplace. It seemed that anybody could yell at him.

Another form of workplace bullying was jealousy. Xiang brought his Chinese work ethics and work fever to the workplace. He worked very hard, coming to work at 7:30 am and going home at 6:00 pm, in contrast to many of his colleagues who came to work around 10:30 am and left at 3:00 pm, plus a one-hour lunch time. He had outstanding achievements in his research, evidenced in his obtaining a $\mathrm{B}$ grade in the nationally administered $\mathrm{PBRF}^{1}$ assessment, the highest grade and the only one of that grade at the polytechnic. His research outputs stunned his colleagues, especially those who had never published anything in their lives. One of them said bluntly: "Xiang, whatever I do, I can never achieve what you have done in terms of research. I can never write an article of your standards for publication." Xiang's achievements, however, did not bring him any advantage. Instead, they brought about his colleagues' jealousy, resentment, alienation, and marginalisation. They felt threatened and uncomfortable, working with a "merciless" Chinese in an open office that accommodated 5 people. The "Merciless" was a nickname coined for Xiang by his colleagues. Its implication was not difficult to decode. Gradually, he seemed to become familiar with his colleagues' yelling, taunting, jeering, and sneering. He did not want to waste his time fighting against such racial discrimination and bullying. He knew he would never win in such a work environment.

\section{A new career advancement}

Having experienced the impenetrable glass ceiling barriers and institutional and interpersonal racism at the polytechnic, seeing no hope of any further career development, Xiang made a bold decision to jump to another higher education institution.

He applied for a job advertised by a university in the same city. He was competing with three other candidates that had been offered an

${ }^{1}$ PBRF $=$ Performance-Based Research Fund. It is administered by the Tertiary Education Commission (TEC) of New Zealand to assess the research performance of lecturers and researchers working in higher education institutions, ranking $\mathrm{A}, \mathrm{B}, \mathrm{C}$, and $\mathrm{E}$ (Emerging Researcher), with $\mathrm{A}$ as the highest. 
interview: one local Kiwi, one from South Africa, and one from the UK. The head of the school invited them to have dinner at his home, a way to assess each contender's interpersonal communication skills and suitability for the job. Xiang successfully got a senior lecturer appointment. He felt very lucky and very grateful to have this appointment and was determined to use his talent, experience, his social and cultural capital to help his school to market its branding, build relationships with top Chinese universities, and recruit more Chinese students to study in the school to increase the school's coffer.

He taught four internal (face-to-face) courses and one extramural (distant learning) course. There were over 100 students in some of his classes. More than one third of them were Chinese students. His classes were very popular and students, domestic and international, loved his classes. His effective communication and instructional skills empowered his students to adapt to his teaching. The students were happy to be exposed to a different teaching pedagogy. He became a shining star. He received many students' nominations as the best lecturer in the school. Xiang played a critical role in assisting his school to internationalize its programmes. Within his ten-year tenure at the university, he initiated 10joint programmes with 7 Chinese top universities. These programmes included $0.5+1.5,1+1,3+1+1.5$ postgraduate programmes, $2+2$ and $3+1$ and $1+3$ undergraduate programmes ${ }^{2}$, and student and staff exchange programmes. Over 150 Chinese students had studied or were studying under these programmes. These initiatives contributed over five million dollars to the university's coffer. The university closed one of the schools because of the low enrolments. Xiang's school never experienced such a crisis - the presence of these Chinese students guaranteed the job security of the school. In addition, these initiatives generated opportunities for the school faculty to visit Chinese partner universities to engage in teaching, research, conferences, and professorial workshops, and for the partner universities' faculty to visit New Zealand to engage in academic and research activities. Xiang's involvement in and contribution to international education not only generated revenues for the university, but fuelled the university's branding and reputation in the competitive Chinese education market.

In spite of his heavy teaching loads and his excessive involvement in international education (which was not included in this job description), he managed very effectively to publish20 journal articles, 16 book chapters, 2 books, and 20 conference papers, and he was invited by universities in New Zealand, Australia, Malaysia, and China to give presentations on teaching and providing pastoral care to international students. In a short span of his tenure at the university, he had attracted over 800 citations which demonstrated his impact on research in the discipline. In the third round of the national PBRF assessment in 2012, again he achieved a B grade. Of the 63 academic faculties in the school, only 10 staff members achieved a B grade and 17 a $\mathrm{C}$ grade. There was no A grade in the school. Some professors and associate professors obtained a B grade. This showed that Xiang had become one of the highly productive researchers in the school.

\section{Cultural differences in communication style}

Having been influenced by his cultural tradition, Xiang always kept a lower profile. Xiang kept quiet, believing that senior leaders would

${ }^{2} 1+1$ and $0.5+1.5$ Postgraduate programmes mean that Chinese students study six months or one year in China, and one or one year and a half at Massey University and successful students will get a Master's degree. The $2+2$ and $3+1$ and $1+3$ undergraduate programmes refer to initiatives on which Chinese students study in China from one to three years and come to New Zealand to study for one to three years and get a bachelor degree or a certificate. know what he had done and deliver adequate rewards accordingly. Unlike him, his Kiwi colleagues would like to loudly advertise themselves, using hyperboles, when they or their students had made some small achievements, such as a student publishing a piece of news in a newspaper, winning an insignificant prize, and giving some positive feedback, and lecturers meeting with a foreign guest, visiting a local high school, and giving a presentation to a business forum. They would like to publicize these throughout the whole school or college, making these small things sound extremely important. Xiang did not like this kind of practice. There is a Chinese saying that discourages him from taking an assertive approach: An empty vessel makes the loudest noise.

Although he had initiated many joint programmes that had generated a lot of revenues, he never made any claim for his important contributions. Only a small number of his colleagues in the school knew that those international programmes were initiated, supported, and maintained by him. Except a couple of people, nobody knew that he had spent hundreds of hours drafting and translating agreements, communicating with and visiting partner universities, providing pastoral care to the students under these programmes, and hosting and looking after visitors and senior leaders from partner universities. When they arrived in New Zealand, these Chinese students preferred to seek all kinds of personal or academic support from him, such as choosing a right topic for their research report, correct use of the APA citation style ${ }^{3}$, the use of Endnote ${ }^{4}$, advice on course selection, finding a part-time job, and how to write an assignment.

These activities consumed a significant amount of his time that was often ignored by the head of the school (HoS). In an annual performance review, the HoS said bluntly: "You have the lightest world load in school. I have arranged another job for you -- marking assignments and providing pastoral care for another lecturer." There were 22 postgraduate students in this class, four assignments, about 2,500 words each. This means he would mark assignments of 220,000 words, not to mention writing comments and giving feedback. Xiang was stunned and puzzled: He taught 5 courses and many other colleagues taught only 3 courses. Some lecturers taught classes in one semester and were given time for research in another semester. In the eye of the HoS, his any contribution in international education and pastoral care for international students was insignificant. The HoS deliberately had turned a blind eye to what he had done. He realized he had been reduced to an intellectual collie. Without making any complaints, he taught his three courses in and semester and marked the four assignments for another lecturer.

Xiang's amicable personality and strong work ethics had won his colleagues' appreciation. He tried to integrate himself into the discourse and organisational culture of the university in order to cross cultural borders by changing his communication styles and life habits. However, he came to understand that such an integration and change were very difficult for him. For example, his colleagues liked to talk about sports, politics,movies, tourism,and gardening, have lunch together and drink coffee in bars, hold birthday parties, invite colleagues and friends to dinner at home, and have binge drinking in town. It was through these social activities that collegial relationships, especially relationships with the HoS and other senior

${ }^{3}$ APA (American Psychological Association) style refers to the rules established by the American Psychological Association for citing sources used in writing ${ }^{4}$ EndNote is a software tool for managing bibliographies, citations and references in writing 
leaders, were developed and strengthened. However, Xiang did not like these activities. He brought his own lunch because he did not like the foods supplied at the campus café, nor did he enjoy coffee and binge drinking. He was interested in international politics - that was his special area, anyway - but he had little interest in sports, such as New Zealand rugby, the All Blacks, the Melbourne Cup, the Sevens Wellington, and horse racing. Not sharing common interests with his colleagues seemed to erect a barrier to his relationships with his colleagues. He felt that he had been marginalised; yet it was a selfimposed marginalisation.

\section{The impenetrable glass ceiling in academic promotions}

Xiang's outstanding achievements in teaching, research, and services were not duly recognised by the college and the university. He failed six times in applying for academic promotions from Senior Lecturer Range 1 to Range 2. Every time, he received the same letter with a different date from the university's HR manager, advising him of his unsuccessful application, without any further comments and feedback.

Hearing his repeated failures, one of his colleagues came to see him, revealing some secrets in academic promotions which Xiang had never heard of before. She failed in applying for the same level of promotion the year before. She requested that the college provide her with the "support letter" by the HoS. To her utter surprise, what was stated in the letter was totally irrelevant to her situation. When the "errors" were thus discovered, the college compensated her by promoting her to Senior Lecturer Range 2, without making a collegewide announcement. She advised him do the same thing by requesting a copy of the support letter by the HoS. He followed her advice. The Pro-Vice Chancellor (PVC) of the college did not supply the sensitive "support" letter. Instead, she sent a letter that incorporated the ideas from the support letter by the HoS:

\section{Dear Xiang Qin,}

I have now had an opportunity to review your application, your HoS comment, and the Committee's recommendation. As a general observation, promotions from SL Range 1 to SL Range $2^{5}$ arevery hard to obtain and many acreers ${ }^{6}$, especially those from ESL background, do not advance beyond this point. Your HoS was uncertain on some points concerning your research, and as therewas NO evidence on reviews, citations or other measures of yourworks' reception by the scholarly community, she had little on which to base a more positive recommendation for pomotion. My advice therefore is to try to publsh in higher quality journals, and to keep contributing in all areas, including teaching and services.I hope this helps.

Regards

XXX

Although Xiang had not received the actual "support letter" by the HoS, the PVC's letter demonstrably showed that the HoS had not provided the university's Promotions Committee with an honest "support letter". Xiang had obtained a B grade in the national PBRF assessment, the same grade as hers (but she was a professor), but the PVC's letter stressed the causes of his failure in application: There was no evidence of his research impact on the research community. The HoS's personal, subjective, biased, and prejudiced judgement of the quality and quantity of his research outputs killed his opportunity and rights for academic promotions. The Google Scholar citation statistics

${ }^{5} \mathrm{SL}=$ Senior Lecturer

${ }^{6}$ The typos were the original. showed that Xiangas a Senior Lecturer Range 1 had more citations (812) than she did (363) as full professor. The HoS had obviously told a lie. One could not achieve a PBRF B grade without having some impact on the scholarly community. Xiang's achievements in research as a PBRF B grader, his heavy involvement in international education, the joint programmes he had initiated, the revenues generated from these programmes, and his excellence in teaching were all excluded from the "support letter". The so-called "support letter" was in effect a killing letter, which the HoS used to prevent Xiang from breaking the glass ceiling she had deliberately erected. The letter by the HoS, together with the "Priority List" that advises the Committee who should be promoted and who should not, eventually determined the fate of the applicants. The existence of the Promotions Committee was nominal only; it was used as a political mechanism, or rubber stamp, for the HoS to legitimately justify her decisions to promote her favourites and to screen out those who remained outside her personal circle.

The PVC's letter dealt a disastrous blow to Xiang. The message was very loud and clear: He had reached the glass ceiling as a Senior Lecture Range 1 (the lowest class within the senior lecturer range) and any further career development was unlikely. There was no evidence to prove that the PVC had ever read Xiang's application that contained all the critical information about his teaching, research, and services. The PVC had little knowledge of what Xiang had achieved and what contributions he had made for the university. The "support letter" by the HoS was the only source of information on which the decision was made.

Xiang's repeated failures in his applications for academic promotion and the school's injustice and mistreatment caught attention of some of his colleagues. They twice approached the HoS, expressing their concerns that Xiang was not getting any recognition for his work. To quell the disquiet that arose in the school, she reluctantly gave a small acknowledgement to his contribution to the school's international education by awarding him a certificate. Many of the staff members were unaware that Xiang did all the work for the school's international education because the HoS and the college's web news never mentioned his name when reporting school's international joint programmes. The HoS had deliberately hid his name, attributing all the success to her own "internationalisation strategy". Screening Xiang out of academic promotion would enable her to reap all the rewards and success for her leadership. She thus created an impression that all the success in international education was attributed to her leadership.

After the award ceremony, the HoS held a serious talk with Xiang. She blamed the university's academic promotion system that prevented him from getting promoted. She assured him that she had been always supportive of his applications for promotion. Xiang sensed her hypocrisy and falsely expressed his gratitude for her support. She concluded by saying: "If I were you, I would find a job elsewhere and say good-bye to the university. The university has failed you six times, who knows it may fail you a seventh or an eighth time. You cannot find your future career advancement at this university." This final message added more pains to his already bleeding heart. He knew now that he was not welcomed in this school, at least not by the HoS who had supreme power to determine staff members' fate. Her message corroborated the PVC's comment that his career path had come to an end at this university.

One week later, the university announced the results of the university leadership survey. The results took the school by surprise - the level of satisfaction was very low in the school: 


\begin{tabular}{|l|l|}
\hline Survey questions & Response rate \\
\hline Discrimination is prevented at the university & $41 \%$ \\
\hline There is an equal opportunity for all staff & $21 \%$ \\
\hline Bullying is prevalent at the university & $51 \%$ \\
\hline $\begin{array}{l}\text { The reward and recognition I receive from this job are } \\
\text { fair }\end{array}$ & $22 \%$ \\
\hline The university recognises the contribution of the staff & $33 \%$ \\
\hline The way my performance is evaluated is fair & $32 \%$ \\
\hline $\begin{array}{l}\text { There are enough opportunities for my career to } \\
\text { progress at the university }\end{array}$ & $24 \%$ \\
\hline
\end{tabular}

The survey results captured a broad picture of the school's organisational culture. Xiang did not realise that, like him, other colleagues in the school had also suffered from workplace bullying, discrimination, inequality, and lack of recognition and career opportunities. Nearly half of his colleagues felt bullying was prevalent and staff's contribution was not duly recognized. He was not the only individual that had been victimised in such a repressive, unsupportive, and unwelcoming work environment. He admired his colleagues' bravery and courage to approach the HoS to express their concerns over the injustice, inequality, and unfair treatment towards him, an individual who had done so much for the school, yet without broadcasting his achievements, and who had generated lots of revenues to help the school to prevent a likely closure, like the other school. He was very grateful to their colleagues for the emotional and moral support during his repeated failures.

\section{Discussion}

The above case study illustrates the challenges encountered by new NESB immigrants represented by Xiang in seeking employment and working in a predominantly white higher education institution. Cultural, ethnic, and linguistic differences are associated with experience of overt and covert interpersonal and institutional racism, biases, discrimination, and status inequality. Such differences made NESB faculty members have "outsider" status and peripheral rather than central (full) memberships in the community of practice.

It is highly relevant to use the social closure theory to analyse the issues of glass ceiling effects in higher education and inadequate recognition of the contribution by NESB faculty in terms of rewards, academic promotions, and senior management roles. The concept of social closure holds that "status groups create and preserve their identity and advantages by reserving certain opportunities of members of the group" [3]. Exclusion becomes a routine practice to maintain stratification hierarchy and the hegemonic status of the group, and normalise and perpetuate the glass ceiling effects, and the advantages for the ingroup and exclusion of the outgroup [4]. Social closure influences individuals' perceptions in the psychological process and creates and recreates social and status inequality. According to status construction theory, social inequality is formed and hierarchies of status, esteem, and influence emerge when members of at least two categorical interdependent groups regularly cooperate to fulfil expectations and achieve anticipated goals in a particular context [5]. Participants hold their status beliefs about the status hierarchies and the categorical distinction associated with general competence and skills. Differences in ethnicity, language and culture as barriers to cultural and social inclusion can lead to perceiving NESB faculty members as an out-group, as peripheral members of the community, to be treated differently from the dominant community.
These two theories- the theory of social closure and the status construction theory- can be used as a framework to analyse the challenges facing Xiang in his job hunting, and the issues of bullying and interpersonal and institutionalized racism in the workplace in higher education in New Zealand. In spite of his doctoral degree from the U.S.A, he was socially and culturally excluded. It took him a long time to find a job that roughly matched his academic qualifications. He was barred from entering into the job market in the academy dominated by the white majority where racism has been a serious problems and "the academy is racially biased" [6]. In the workplace, his white colleagues, who even did not have his high academic status in terms of qualification, assumed superior social status and could yell at him any time at their whims without any hesitation. The senior managers who opposed recruiting NESB faculty gave him a hard time, considering him as a liability, rather than an asset that could bring value to the institution.

Xiang became a victim of covert interpersonal and institutionalised racism. One type of such covert racism is the concept of hair-splitting based on "trivial technicalities or subjective calls", "minor, arbitrary, and inconsequential factors... hairline differences" [7] that favour in group members but disadvantage NESB out-group members in terms of recruitment and promotions. Such an arbitrary and subjective hair-splitting practice prevents NESB professionals from entering into the community practice, from promotions to a higher academic ladder and to a management role. In this case study, Xiang's higher qualifications, his contribution to the university's internationalisation programmes and financial health, and his achievements in research and teaching did not enable him to escape the tentacles of covert racism in academia. Whatever achievements he had made could not help him break the stained glass ceiling for upward mobility, even he had excelled in many aspects of the academia and had done better than his white colleagues. The stained glass ceiling was both subjective and realistic; it positioned NESB faculty within the steely confines of permanence. It is impenetrable. The participation of NESB faculty in higher education, presumably contributing to internationalization that might add some weight to university ranking, was perceived as lowering the education standards by those who uphold the standards, values, and norms of the dominant group and wish to maintain the status quo in the academy that is in the "power of elite racism" [8]. Van Dijk [9] defines elite racism as the "historically rooted dominance of whites (Europeans) over Others." "Others" here refers to the nondominant group that encounter everyday racism that involves "the everyday, mundane, negative opinions, attitudes, and ideologies and the seemingly subtle acts and conditions of discrimination against minorities, namely those social cognitions and social acts, processes, structures or institutions" [9]. Xiang had discovered this painful truth of everyday racism, but was not sure whether he should continue to fight for social justice or just accept his preordained choices.

\section{Conclusion}

This case study, through the voices of a Chinese academic named Xiang Qin, reports his acculturative experiences tinged with hardships, setbacks, pains, bitterness, and plights. His advanced qualification from the U.S.A. was not a guaranteed entry ticket for employment in the New Zealand labour market. His repeated failures in seeking employment and his experiences in the workplace reflect his awareness and understanding of overt and covert interpersonal and institutionalized racism, bullying, discrimination, marginality that were prevalent in higher education institutions in New Zealand. He encountered many racialized barriers that prevented his legitimate 
Citation: Li M (2016) Crossing Border: The Acculturative Experiences of a Chinese Migrant Academic New Zealand. Int J Journalism Mass Comm 3: 123. doi: https://doi.org/10.15344/2349-2635/2016/123

entry into the academic community and his aspirations to upward mobility and academic promotions, in spite of his achievements in teaching, research, and services, his understanding of the norms and standards of the academic culture, and his willingness to adapt and accommodate. The differences in ethnic, cultural, and linguistic backgrounds were not interpreted as mere differences; they were perceived as alternative perspectives that were denigrated, otherized, and racialized. In addition, Xiang's non-assertive and lowkey communication style was found to be culturally incompatible todevelop healthy relationship with colleagues and form social networks in the workplace that are critically important for career advancement, academic promotions and upward mobility. On the bumpy road to cross racialized barrier into the white-dominated academic discourse, Xiang had a long way to go.

\section{Competing Interests}

The author declare he has no competing interests exists.

\section{References}

1. Chelsler M, Lewis A, Crowfoot $J$ (2005) Challenging racism in higher education: promoting justice. New York: Rowman \& Littelfield Publisher, Inc.

2. Lave J, Wenger E (2002) Legitimate peripheral participation in communities of practice. In R. Harrison, F. Reeve, A. Hanson, \& J. Clarke (Eds.), Supporting lifelong learning: perspectives on learning (Vol. 1, pp. 111-126). London: The Open University.

3. Tomaskovic-Devey D (1993) Gender and racial inequality at work: The sources and consequences of job segregation. Ithaca, NY: ILR Press.

4. Jackson JFL, Leon RA (2010) Enlarging our understanding of glass ceiling effects with social closure theory in higher education. In J. C. Smart (Ed.), Higher education: handbook of theory and research (Vol. 25, pp. 351-379) London: Springer Science+Business Media B.V.

5. Ridgeway CL (2006) Status construction theory. In P. J. Burke (Ed.) Contemporary social psychological theories (pp. 301-323). Stanford, Calif.: Stanford Social Sciences.

6. Scheurich JJ (1993) Toward a White discourse on White racism Educational Research 22: 5-10.

7. Reyes M, Halcon JJ (1998) Racism in academia: The old wolf revisited Harvard Educational Reviews 58: 299-314

8. Johnsrud LK, Sadao KC (1998) The common experience of "otherness" Ethnic and racial minority faculty. The Review of Higher Education 21: 315342.

9. Van Dijk TA (1993) Elite discourse and racism. Newbury Park, CA: SAGE. 